\title{
GAMBARAN EMPATI PADA MAHASISWA FAKULTAS KEDOKTERAN UNIVERSITAS SAM RATULANGI ANGKATAN 2010
}

\author{
${ }^{1}$ Merry C. Warokka \\ ${ }^{2}$ Taufiq F. Pasiak \\ ${ }^{2}$ Djon Wongkar
}

\author{
${ }^{1}$ Kandidat Skripsi Fakultas Kedokteran Universitas Sam Ratulangi Manado \\ ${ }^{2}$ Bagian Anatomi-Histologi Fakultas Kedokteran Universitas Sam Ratulangi Manado \\ Email: merrychristy12092@yahoo.com
}

\begin{abstract}
Empathy is an important factor to support a positive relationship between physician and patient. Medical students as candidates for physician should have a good empathy. The lack of study and literature that discusses students empathy in North Sulawesi made researchers aimed to see an overview of empathy in medical students batch 2010 of Sam Ratulangi University.This study is a quantitative descriptive. The data were collected using a cross sectional design. The questionnaires was completed by 75 medical students at University of Sam Ratulangi who active on duty as co-assistant at RSUP Prof. dr. R.D Kandou. This study showed empathy scores of medical students high (66\%), moderate (33\%), and low (1\%). Results of average scores of empathy women is higher than men. High empathy based on quantitative calculations do not mean to have a good empathy. Study with questionnaires more specific for medical students, qualitative study on patients, and method of longitudinal study, researchers suggested that can assess the quality of empathy for the co-assistant.
\end{abstract}

Keywords: emphaty, medical student, co-assistant

\begin{abstract}
Abstrak: Empati merupakan faktor yang penting untuk menunjang terjalinnya hubungan yang positif antara tenaga medis dan pasien. Mahasiswa kedokteran sebagai calon tenaga medis seharusnya memiliki empati yang baik. Minimnya penelitian dan sumber literatur yang membahas empati pada mahasiswa di Sulawesi Utara membuat peneliti bertujuan untuk melihat gambaran empati pada mahasiswa Fakultas Kedokteran Universitas Sam Ratulangi angkatan 2010. Penelitian ini bersifat deskriptif kuantitatif dengan desain penelitian cross sectional. Angket skala empati diisi oleh 75 mahasiswa Fakultas Kedokteran Universitas Sam Ratulangi yang sedang aktif menjalankan tugas sebagai co-assistant di Rumah Sakit Umum Pendidikan Prof. dr. R.D Kandou. Penelitian ini menunjukkan hasil empati tinggi (66\%), sedang (33\%), rendah (1\%). Hasil skor rata-rata empati perempuan lebih tinggi dari pada lakilaki. Empati yang tinggi berdasarkan perhitungan kuantitatif belum sepenuhnya berarti memiliki empati yang baik. Penelitian dengan alat ukur yang lebih spesifik, penelitian secara kualitatif terhadap pasien, serta penelitian dengan metode longitudinal disarankan peneliti agar dapat menilai kualitas empati para co-assistant.
\end{abstract}

Kata kunci: empati, mahasiswa kedokteran, co-assistant

Pada dasarnya manusia diciptakan untuk hidup saling berdampingan. Manusia hidup tidak hanya mengandalkan dirinya sendiri sehingga manusia disebut juga sebagai makhluk sosial yang berarti membutuhkan orang lain dalam proses kelangsungan hidupnya. Hal ini mengakibatkan diperlukannya suatu interaksi sosial di 
dalam kehidupan manusia.

Kemampuan manusia untuk memahami, beradaptasi, dan berinteraksi dengan lingkungan sekitar tentunya melibatkan peranan otak. Melalui kerja sama antara otak dan sistem saraf, manusia dapat menerima, memroses, dan merespon informasi dari lingkungannya.

Neurosains adalah ilmu yang mempelajari sistem saraf, terutama mempelajari neuron atau sel saraf, ${ }^{1}$ dalam hal ini otak. Perkembangan berbagai disiplin ilmu terjadi untuk mempelajari hubungan peranan otak dan perilaku manusia. Perpaduan kerja sama interdisiplin ilmu seperti ilmu psikologineuro dan kognitif menciptakan disiplin ilmu neurosains kognitif, yang menghubungkan otak dan aspek lain sistem saraf, khususnya antara otak dengan pemrosesan kognitif, serta dengan perilaku. $^{2}$

Manusia menghabiskan banyak waktu dalam kehidupannya dengan cara mengamati serta mencoba memahami baik tindakan ataupun perasaan orang lain melalui interaksi sosial. Berdasarkan Theory of Mind, kesuksesan dari suatu interaksi sosial salah satunya membutuhkan empati. $^{3}$ Empati merupakan kemampuan seseorang untuk memahami apa yang orang lain pikirkan dan rasakan pada situasi tertentu. Jadi, kemampuan berempati diperlukan untuk menunjang keberadaaan individu dalam interaksi sosialnya. ${ }^{4}$

Proses empati pada manusia mulai menarik perhatian untuk diteliti akibat ditemukannya mirror neuron system pada otak monyet. Mirror neurons bertanggung jawab dalam proses peniruan perilaku orang lain. Penelitian pada neurosains sosial menunjukan bahwa perilaku imitatif (meniru) merupakan prasyarat dasar untuk pengembangan keterampilan sosial. ${ }^{5}$ Selain sebagai dasar untuk perilaku imitatif, mirror neuron system juga merupakan dasar untuk memfasilitasi individu memahami tindakan dan bahkan emosi orang lain melalui mekanisme "simulasi". ${ }^{5}$

Empati merupakan faktor yang penting untuk menunjang terjalinnya hubungan yang positif antara tenaga medis dan pasien. ${ }^{6}$ Pada dasarnya, setiap pasien ingin tenaga medis yang merawatnya mengerti akan penyakit yang dideritanya. Empati tenaga medis terhadap pasien serta kesadaran pasien akan perhatian dan kepedulian yang tenaga medisnya berikan, diharapkan dapat meningkatkan hasil klinik yang lebih baik. ${ }^{6}$

Mahasiswa kedokteran sebagai calon tenaga medis seharusnya memiliki empati yang tinggi. Berbeda dengan apa yang diharapkan, hasil tes psikometri di Fakultas Kedokteran Universitas Indonesia mendapatkan hasil empati dan rasa kemanusiaan mahasiswa tahun pertama dan keempat Fakultas Kedokteran Universitas Indonesia rendah. $^{7}$

Sebuah penelitian yang dilakukan oleh Kimbal terhadap kualitas pelayanan di Rumah Sakit Umum Prof. dr. R.D. Kandou berpendapat bahwa pelayanan kesehatan yang berkualitas salah satunya dinilai dari empati tenaga kesehatan yang bertugas. ${ }^{8}$ Menurutnya, empati tenaga kesehatan di Rumah Sakit Umum Prof. dr. R.D. Kandou masih rendah. Berdasarkan hasil observasi yang ditemui di lokasi, Kimbal menyimpulkan bahwa pelayanan kesehatan yang melibatkan interaksi langsung dengan pasien di Rumah Sakit Umum Prof. dr. R.D. Kandou didominasi oleh residen, perawat, serta co-assistant yang masih dalam tahap pembelajaran untuk meraih gelar dokter.

Hubungan antara tenaga medis dengan pasien yang dominan bersifat vertikal paternalistik, mahasiswa kedokteran yang cenderung terlihat sibuk dengan segala tugas dan tanggung jawab baik dalam praktiknya sebagai co-assistant atau di lingkungan kampus maupun masyarakat, tidak jarang membuat masyarakat atau pasien merasa kurang diperhatikan karena seakan-akan mereka hanya sibuk mengejar target untuk menyelesaikan segala tugas yang ada. Hal ini mungkin bisa terjadi karena masih rendahnya empati.

Berdasarkan uraian di atas, disertai minimnya penelitian dan sumber literatur yang membahas empati pada mahasiswa di 
Sulawesi Utara, maka peneliti ingin melihat gambaran empati pada mahasiswa Fakultas Kedokteran Universitas Sam Ratulangi angkatan 2010.

\section{METODE PENELITIAN}

Penelitian ini menggunakan metode penelitian deskriptif dengan desain penelitian cross-sectional study. Sampel 75 mahasiswa Fakultas Kedokteran Universitas Sam Ratulangi yang sedang aktif menjalankan tugas sebagai $\mathrm{CO}^{-}$ assistant di Rumah Sakit Umum Pendidikan Prof. dr. R.D Kandou.

Data dalam penelitian ini termasuk data primer kuantitatif, diperoleh dengan menggunakan angket khusus skala empati yang disusun oleh Purnomo. ${ }^{9}$

Kategorisasi dalam penelitian ini dibagi menjadi tiga kategori, yaitu: ${ }^{10}$

1. rendah (batasan $X<(\mu-1 \sigma)$

2. sedang $(\mu-1 \sigma) \leq X<(\mu+1 \sigma)$,

3. tinggi (batasan $(\mu+1 \sigma) \leq X)$.

Keterangan:

$\mathrm{X}=$ skor responden

$\mu=$ rerata hipotetik

$\sigma=$ standar deviasi hipotetik

Rumus untuk menentukan rerata hipotetik sebagai berikut $:^{10}$

$\mu=\frac{1}{2}\left(\mathrm{i}_{\max }+\mathrm{i}_{\min }\right) \Sigma \mathrm{k}$

Keterangan

$\mu=$ rerata hipotetik

$\mathrm{i}_{\max }=$ skor maksimal item

$\mathrm{i}_{\min }=$ skor minimal item

$\Sigma \mathrm{k}=$ jumlah item

Rumus untuk menghitung standar deviasi hipotetik $(\sigma)^{10}$ $\sigma=\frac{1}{6}\left(X_{\max }-X_{\min }\right)$

Keterangan:

$\sigma=$ standar deviasi hipotetik

$\mathrm{X}_{\max }=$ skor maksimal yang dapat diperoleh responden

$\mathrm{X}_{\min }=$ skor minimal yang dapat diperoleh responden

Hasil yang diperoleh kemudian diolah menggunakan program SPSS 20.00.

HASIL PENELITIAN

Karakteristik Responden Penelitian

Deskripsi karakteristik responden menurut usia dapat dilihat pada tabel 1 .

Tabel 1. Distribusi Usia Responden

\begin{tabular}{ccc}
\hline Usia & Frekuensi & $(\%)$ \\
\hline 21 & 1 & 1,33 \\
22 & 24 & 32,00 \\
23 & 46 & 61,33 \\
24 & 4 & 5,34 \\
Total & 75 & 100,00 \\
\hline
\end{tabular}

Deskripsi karakteristik responden menurut jenis kelamin dapat dilihat pada Tabel 2.

Tabel 2. Distribusi Jenis Kelamin Responden

\begin{tabular}{lcc}
\hline Jenis Kelamin & Frekuensi & $(\%)$ \\
\hline Laki-laki & 31 & 41,33 \\
Perempuan & 44 & 58,67 \\
Total & 75 & 100,00 \\
\hline
\end{tabular}

\section{Hasil Interpretasi Skala Empati}

Kategorisasi skala empati dapat dilihat pada tabel 3 dan gambar 1.

Tabel 3. Kategorisasi Hasil Skala Empati

\begin{tabular}{lcc}
\hline Kategori & Jumlah & $(\%)$ \\
\hline Rendah & 1 & 1,3 \\
Sedang & 25 & 33,3 \\
Tinggi & 49 & 65,3 \\
Total & 75 & 100,0 \\
\hline
\end{tabular}

Kategorisasi hasil skala empati berdasarkan jenis kelamin dapat dilihat pada Tabel 4.

Perbadingan hasil skor rata-rata empati berdasarkan jenis kelamin dapat dilihat pada Tabel 5.

Tabel 4. Kategorisasi Hasil Skala Empati Berdasarkan Jenis Kelamin

\begin{tabular}{lccc}
\hline \multirow{2}{*}{ Kategori } & \multicolumn{2}{c}{ Jenis Kelamin } & \multirow{2}{*}{ Total } \\
\cline { 2 - 3 } Laki-laki & Perempuan & \\
\hline \multirow{2}{*}{ Rendah } & 1 & 0 & \\
& & & \\
Sedang & 9 & 16 & 25 \\
Tinggi & 21 & 28 & 49 \\
\hline
\end{tabular}




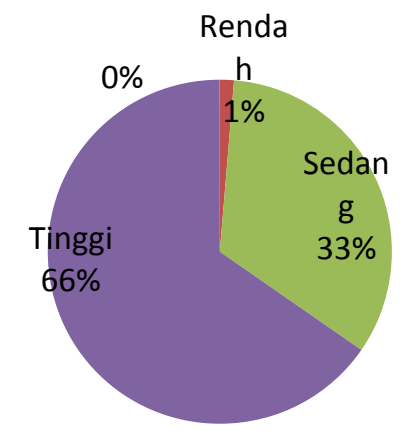

Gambar 1. Hasil skala empati berdasarkan kategori

Tabel 5. Perbadingan hasil skor rata-rata empati berdasarkan jenis kelamin

\begin{tabular}{ccc}
\hline Jenis Kelamin & Jumlah & Rata-rata \\
\hline Perempuan & 44 & 63,11 \\
Laki-laki & 31 & 62,80 \\
\hline
\end{tabular}

\section{BAHASAN}

\section{Deskripsi Karakteristik Responden}

Penelitian ini melibatkan 75 responden. Berdasarkan tabel 1, distribusi usia responden berkisar dari 21-24 tahun dengan persentase terbesar $(61,33 \%)$ pada umur 23 tahun sebesar 46 responden. Hal ini dikarenakan pada saat penelitian ini dilakukan, mahasiswa kedokteran angkatan 2010 yang sedang menjalankan coassistant berada pada tahun kelima pendidikannya untuk meraih gelar dokter. Distribusi responden menurut jenis kelamin terlihat pada tabel 2. Responden penelitian sebesar 75 orang yang didominasi oleh responden perempuan.

\section{Hasil Interpretasi Skala Empati}

Pada Tabel 3 dan gambar 1 terlihat bahwa mayoritas hasil empati dari mahasiswa Fakultas Kedokteran iversitas Sam Ratulangi angkatan 2010 mayoritas tinggi serta pada tabel 5 terlihat hasil skor rata-rata empati perempuan lebih tinggi.

Hasil penilaian empati pada penelitian ini menunjukkan bahwa mayoritas empati pada mahasiswa Fakultas Kedokteran Universitas Sam Ratulangi angkatan 2010 yang menjalankan tugas sebagai coassistant memiliki empati yang tinggi.

Hasil ini diperoleh melalui pengkate- gorisasian yang digunakan hanya untuk mengelompokkan tinggi rendahnya skor responden sehingga mayoritas skor yang diperoleh tinggi belum sepenuhnya berarti co-assistant angkatan 2010 memiliki empati yang baik karena ini berdasarkan penilaian kuantitatif.

Hasil kategorisasi skor responden tersebut bertolak belakang dan tidak sesuai dengan data observasi dan wawancara yang dilakukan oleh Kimbal terhadap kualitas pelayanan kesehatan di Rumah Sakit Umum Pendidikan Prof. dr. R.D. Kandou Manado. Menurut Kimbal empati yang diberikan kepada pasien masih belum baik karena masih terdapat perbedaan antara persepsi yang diharapkan pasien maupun kenyataan yang dirasakan pasien sehingga tenaga medis perlu meningkatkan sikap yang mau mempelajari dan mengetahui kebutuhan personal dari pasien. ${ }^{8}$

Hal ini sesuai dengan wawancara singkat yang sebenarnya tidak direncanakan oleh peneliti karena adanya waktu luang dari beberapa co-assistant saat penelitian berlangsung sehingga terjadi interaksi tanya jawab yang peneliti dapat simpulkan bahwa mereka merasa dengan setiap hari harus mengurus masalah kesehatan pasien serta memeriksa penyakit pasien menjadi alasan bahwa mereka sudah berempati terhadap pasien tersebut yang sebenarnya hal itu bukan merupakan bentuk empati melainkan tugas yang sudah seharusnya mereka lakukan sehingga mereka kurang mempelajari dan mencari tahu kebutuhan personal dari pasien.

Permasalahan di atas menjadi kelemahan dalam penelitian ini yang disebabkan oleh adanya faking good yaitu ketika proses pengambilan data penelitian yang berupa skala, pilihan jawaban yang dipilih oleh para responden adalah jawaban yang positif meskipun jawaban tersebut tidak sesuai dengan keadaan sebenarnya. ${ }^{11}$ Munculnya faking good tersebut disebabkan karena sebagian besar responden mengisi jawaban sendiri yang seharusnya peneliti tanyakan secara langsung kemudian responden menjawab dengan spontan. Hal ini terjadi karena 
selama proses pengambilan data di rumah sakit para co-assistant sebagian besar sibuk dan hanya mempunyai sedikit waktu agar dapat terlibat dalam penelitian sehingga lebih banyak yang bersedia mengisi jawaban sendiri dibanding dibacakan oleh peneliti.

Menurut Anastasi dan Urbina dalam pengisian skala yang diisi sendiri, partisipan memiliki kecenderungan untuk menjawab kearah yang lebih baik (faking good), kecenderungan partisipan untuk faking good muncul dengan alasan untuk melindungi diri sendiri, menghindari kritik, konformitas sosial, serta keinginan untuk diterima secara sosial karena permasalahan mengenai kepuasan kerja dan penilaian. ${ }^{12}$

Kelemahan lainnya dalam penelitian ini yaitu dari alat ukur yang digunakan. Angket skala empati Purnomo tidak khusus dibuat untuk menilai empati pada mahasiswa kedokteran sehingga pernyataan-pernyataan yang ada tidak secara spesifik menyatakan atau menggambarkan bentuk empati yang seharusnya dilakukan sebagai mahasiswa kedokteran dalam tahap co-assistant. Hal ini dapat mengakibatkan kesalahpahaman responden dalam menjawab setiap pernyataan dalam angket. Jika sebagian besar co-assistant memiliki sudut pandang yang sama bahwa mengurus masalah kesehatan pasien sudah merupakan bentuk empati mereka seperti beberapa coassistant yang peneliti wawancarai, dapat mengakibatkan seakan-akan hasil empati tinggi padahal terjadi kesalahan persepsi dalam mengartikan empati.

Banyak penelitian yang menunjukan penurunan empati pada mahasiswa kedokteran terutama saat bertugas pada masa pendidikan klinik. Neumann dkk, melakukan studi literatur untuk membahas penyebab penurunan empati pada mahasiswa kedokteran dan residen. Studi literatur dilakukan menggunakan data berbagai penelitian empati sebelumnya dari Januari 1990 sampai Januari 2010 dengan hasil bahwa tekanan yang dialami mahasiswa kedokteran dan residen seperti kelelahan, penurunan kualitas hidup, rendahnya kesejahteraan serta depresi terlihat sebagai alasan utama terjadinya penurunan empati pada mahasiswa kedokteran dan residen. ${ }^{13}$

Banyaknya beban tugas yang harus dilakukan mahasiswa kedokteran terutama saat menghadapi tugas di klinik sebagai coassistant membuat mereka harus melewati waktu kerja yang panjang dengan keadaan kurangnya tidur dan kurangnya waktu untuk berelaksasi. ${ }^{14,15,16}$ Hal ini juga membuat mereka terfokus pada segala tugas yang ada dari pada memerhatikan aspek kemanusiaan dan pengobatan yang diperlukan pasien, ${ }^{14,17}$ sehingga dapat membuat mereka memandang pasien hanya sebagai tugas yang harus cepat dikerjakan tanpa memerhatikan keadaan emosional pasien yang perlu dukungan atau perhatian dari para co-assistant.

Terdapat perbedaan sudut pandang antara pasien dan dokter terhadap sakit. ${ }^{18}$ Residen maupun co-assistant lebih terfokus kepada penyakit yang dianggap sebagai tugas yang harus dihadapi sedangkan pasien lebih memrioritaskan perasaan dan masalah dirinya yang sakit, mengharapkan perhatian yang lebih, empati, perlakuan yang ramah dan santun dalam upaya penyembuhan yang cepat. ${ }^{18}$ Segala harapan pasien yang memandang bahwa ilmu kedokteran selalu bisa mengobati dan selalu ada cara yang baik untuk menyembuhkan penyakitnya ${ }^{19}$ harus dihadapi oleh para co-assistant serta residen sehingga dapat membuat mereka semakin tertekan dengan banyaknya tanggung jawab yang ada. ${ }^{13}$

Kimbal menilai bahwa pelayanan kesehatan di Rumah Sakit Umum Pendidikan Prof. dr. R.D. Kandou Manado seperti perawatan pasien kebanyakan dilakukan bukan oleh dokter ahli/spesialis tetapi oleh residen atau co-assistant yang sebenarnya masih harus selalu dipantau praktik kerjanya oleh dokter yang profesional. $^{8}$ Hal ini mengakibatkan semakin banyaknya interaksi antara coassistant dan pasien yang dapat menyebabkan penurunan empati pada masa pendidikan klinik. Salah satu alasan yang 
dapat menjelaskan penurunan empati ini ialah terlalu banyaknya pasien yang sakit serta kematian yang sering disaksikan, membuat para co-assistant menjadi tidak terlalu menaruh kasihan terhadap pasien. ${ }^{13}$

Menurut hipotesis Bauer, kemampuan berempati dapat terganggu jika adanya keadaan berlebihan dari sifat yang tidak berperasaan atau kurangnya perhatian pada orang. Kecemasan, ketegangan dan stress yang dialami seseorang dapat mengurangi sinyal mirror neurons. Satu kali muncul penekanan, ketakutan ataupun stress dapat membuat mirror neurons berhenti bekerja. $^{20}$

Hasil penilaian empati pada penelitian ini berdasarkan jenis kelamin menunjukkan bahwa rata-rata nilai skor empati mahasiswa perempuan lebih tinggi dari pada mahasiwa lai-laki. Hal ini bisa dilihat pada tabel 5. Hasil ini sesuai dengan penelitian-penelitian tentang empati berdasarkan jenis kelamin pada mahasiswa kedokteran yang telah dilakukan sebelumnya.

Chen dalam penelitannya terhadap mahasiswa kedokteran mendapatkan hasil bahwa perempuan memiliki skor empati lebih tinggi dari pada laki-laki. ${ }^{21}$ Hal ini sesuai dengan penelitian yang dilakukan pada mahasiswa kedokteran di Portugal, Jepang, Amerika, dan Meksiko yang juga mendapatkan hasil bahwa perempuan memiliki skor empati lebih tinggi dari pada laki-laki. $^{22,23,24,25}$

Banyaknya penelitian yang memperlihatkan hasil bahwa skor empati perempuan lebih tinggi dari pada skor lakilaki melatarbelakangi peneltian SchulteRuther dkk untuk meneliti ada tidaknya perbedaan mekanisme saraf berdasarkan jenis kelamin terkait kognisi sosial emosional. $^{26}$ Hasil penelitian melalui functional magnetic resonance imaging menunjukan bahwa terjadi peningkatan aktivitas saraf lebih tinggi di daerah kanan cortex cerebri lobus frontalis inferior dan sulkus temporal superior pada perempuan dibandingkan dengan laki-laki. Hal ini menunjukan bahwa perempuan melibatkan daerah yang terdapat mirror neuron lebih banyak dari pada laki-laki.

Penelitian lainnya dilakukan oleh Cheng dkk menggunakan elektroensefalografi untuk mengukur irama $\mu(\mathrm{Mu})$ yang dapat diandalkan untuk melihat aktivitas dari mirror neuron manusia. ${ }^{27}$ Hasil penelitian menunjukan bahwa penekanan $\mu$ secara signifikan lebih kuat terhadap perempuan dari pada laki-laki yang berarti lebih tingginya kemampuan empati perempuan dari pada laki-laki.

Penelitian ini memiliki berbagai keterbatasan. Penilaian empati pada penelitian ini hanya menggunakan selfreport atau penilaian terhadap diri sendiri tanpa memerhatikan para pasien yang sebenarnya dapat menilai empati para $\mathrm{co}^{-}$ assistant karena para pasienlah yang menerima empati dari para co-assistant. Hasil penelitian ini diperoleh dengan menggunakan desain penelitian crosssectional yang berarti hanya satu kali pengukuran sehingga belum dapat mewakili secara keseluruhan untuk memantau empati yang sebenarnya seharihari dipraktikan oleh para co-assistant. Perlu diperhatikan dalam penelitian ini bahwa ditemukannya satu co-assistant yang memiliki hasil rendah, sehingga dapat menjadi pertimbangan untuk penelitian lebih lanjut dengan meningkatkan jumlah responden yang diteliti.

\section{SIMPULAN}

1. Mahasiswa Fakultas Kedokteran Universitas Sam Ratulangi angkatan 2010 yang menjalankan tugas sebagai co-assistant mayoritas memiliki empati yang tinggi.

2. Empati yang tinggi berdasarkan perhitungan kuantitatif tidak berarti sudah memiliki empati yang baik.

3. Hasil empati pada perempuan lebih tinggi dari pada laki-laki.

\section{SARAN}

1. Perlu dilakukan penelitian dengan alat ukur yang lebih spesifik untuk mengukur empati pada mahasiswa kedokteran.

2. Perlu dilakukan penelitian secara kualitatif terhadap pasien di Rumah 
Sakit Umum Prof. dr. R.D Kandou karena merekalah yang dapat menilai dan merasakan empati dari para $\mathrm{CO}^{-}$ assistant yang bertugas.

3. Penelitian dengan metode longitudinal disarankan peneliti agar dapat memantau semakin meningkat atau menurunnya empati pada mahasiswa kedokteran.

\section{DAFTAR PUSTAKA}

1. Pasiak T. Tuhan Dalam Otak Manusia. Bandung: Mizan; 2012. h. 132,217.

2. Mandar DS. Peranan Cognitive Neuroscience dalam Bidang Pendidikan. Prosiding SnaPP2011 Sains, Teknologi, dan Kesehatan. 2011;2(1):369.

3. Kanske P, Bockler A, Trautwein FM, Singer $\mathbf{T}$. Dissecting the social brain: Introducing the EmpaToM to reveal distinct neural networks and brainbehavior relations for empathy and Theory of Mind. NeuroImage. 2015;122:6.

4. Choi D, Watanuki S. Effect of empathy trait on attention to faces: an eventrelated potential (ERP) study. Journal of Physiological Anthropology. 2014;33:4.

5. Horan WP, Iacoboni M, Cross KA, Korb A, Lee J, Nori P, et al. Self-reported empathy and neural activity during action imitation and observation in schizophrenia. NeuroImage: Clinical. 2014;5:100.

6. Glaser KM, Markham FW, Adler HM, McManus RP, Hojat $M$. Relationships between scores on the Jefferson Scale of physician empathy, patient perceptions of physician empathy, and humanistic approaches to patient care: A validity study. Med Sci Monit. 2007;13(7):291.

7. Rasa empati calon dokter rendah. 2012 Feb 24 [cited 2015 Oct 25]. Available from:

www.health.kompas.com/read/2012/0 2/24/06563961/Rasa.Empati. Calon.Dokter.Rendah

8. Kimbal ML. Kualitas pelayanan kesehatan rawat inap kelas tiga di rumah sakit umum pusat Prof. dr. R.D. Kandou Manado [disertasi]. [Bandung]: Univeritas Padjajaran; 2013.
9. Purnomo A. Hubungan antara kecanduan gadget(mobile phone) dengan empati pada mahasiswa. [Skripsi]. [Yogyakarta]: Universitas Islam Negeri Sunan Kalijaga; 2014.

10. Azwar S. Penyusunan skala psikologi. Yogyakarta: Penerbit Pustaka Pelajar; 2003.

11. Tentama F. Peran Kepuasan Kerja Terhadap Kinerja Pada Guru Pegawai Negeri Sipil (PNS) di Yogyakarta. Jurnal Psikologi Undip. 2015 Apr 1;14(1):1-8.

12. Anastasi, A. \& Urbina, S. Psychological testing. Edisi ketujuh. Jakarta: PT Indeks; 2007.

13. Neumann $M^{1}$, Edelhäuser $F$, Tauschel D, Fischer MR, Wirtz M, Woopen C, et al. Empathy decline and its reasons: a systematic review of studies with medical students and residents. Acad Med. 2011;86(8):9961009.

14. Chen D, Lew R, Hershman W, Orlander J. A cross-sectional measurement of medical student empathy. J Gen Intern Med. 2007;22:1434-1438.

15. Stratton TD, Saunders JA, Elam CL. Changes in medical students' emotional intelligence: An exploratory study. Teach Learn Med. 2008;20:279-284.

16. Bellini LM, Baime M, Shea JA. Variation of mood and empathy during internship. JAMA. 2002;287:3143-3146.

17. Hojat M, Mangione S, Nasca TJ, et al. An empirical study of decline in empathy in medical school. Med Educ. 2004;38:934-941.

18. Boediardja, SA. Komunikasi dengan Empati, Informasi dan Edukasi: Citra Profesionalisme Kedokteran. Maj Kedokt Indon. 2009;59:147-50.

19. Schrauth M, Kowalski A, Weyrich $P$, Begenau J, Zipfel S, Nikendei C. Self-image, the real physician and the ideal physician: A comparison of medical students from 1981 and 2006 [in German]. Psychother Psychosom Med Psychol. 2009;59:446-453.

20. Bauer J. Why I Feel What You Feel. Communication and the Mystery of 
Mirror Neurons [in German]. Hamburg, Germany: Hoffmann und Campe; 2005.

21. Chen DCR, Kirshenbaum DS, Yan J, Kirshenbaum E, Aseltine RH. Characterizing changes in student empathy throughout medical school. Medical Teacher. 2012;34:305-11.

22. Magalhaes E, Salgueira AP, Costa P, Costa MJ. Empathy in senior year and first year medical students: a cross-sectional study. BMC Med Educ. 2011;11:52.

23. Kataoka HU, Koide N, Ochi K, Hojat M, Gonnella JS. Measurement of Empathy Among Japanese Medical Students: Psychometrics and Score Differences by Gender and Level of Medical Education. Academic Medicine. 2009;84:1192-7.

24. Hojat M, Gonnella JS, Nasca TJ, Mangione S, Veloski JJ, Magee $M$.
The Jefferson Scale of Physician Empathy: Further psychometric data and differences by gender and specialty at item level. Acad Med. 2002;77(suppl):S58-S60.

25. Alcorta-Garza A, Gonzalez-Guerrero JF, Tavitas-Herrera SE, RodriguesLara FJ, Hojat M. Validity of the Jefferson Scale of Physician Empathy among Mexican medical students [in Spanish]. Salud Mental. 2005;28:5763.

26. Schulte-Ruther M, Markowitsch HJ, Shah NJ, Fink GR, Piefke M. Gender differences in brain networks supporting empathy. Neuroimage. 2008;42(1):393-403.

27. Cheng $Y$, Lee PL, Yang CY,Lin CP, Hung D, Decety J. Gender Differences in the Mu Rhythm of the Human Mirror-Neuron System. PLoS ONE. 2008;3(5):2113. 